\title{
Non-fatal drowning in under-five rural children of Bangladesh
}

\author{
Syed Hassan Abdullah ${ }^{1}$ and Meerjady Sabrina Flora ${ }^{2}$ \\ ${ }^{I}$ Commanding officer, Bangladesh Army \\ ${ }^{2}$ Professor of Epidemiology, National Institute of Preventive and Social Medicine
}

\begin{abstract}
Drowning has been identified as a major cause of death in children in both developed and developing countries. Non-fatal drowning is several times higher than the fatal drowning. To describe the socio-demographic and environmental attributes of non-fatal drowning in rural children this community based descriptive study was conducted on 122 children having non-fatal drowning events within one year of study period. This study was undertaken in Raigonj sub-district of Sirajgonj district in Bangladesh. Mothers of those children were interviewed using a structured questionnaire. Out of all participants $56.6 \%$ children were 2-4 years of age and male-female ratio was almost equal. Of the total respondent mothers $55 \%$ were illiterate and $41.8 \%$ were below the age of 25 years. Seasonal variation was observed in non-fatal drowning. Rainy season (50.8\%) appeared as the most risky period followed by summer (29.5\%). Higher incidence occurred (53.3\%) between 10 am to $2 \mathrm{pm}$ of the day. Although most of the drowning occurred outside the home, $9 \%$ drowning occurred in water container (like drum, tub) within the home. Pond $(50.5 \%)$ was found as the most common place among open water source. During the occurrence, $23 \%$ child was not accompanied by parents or any caregivers. At the time of drowning, $47.5 \%$ mothers were engaged with usual household work and were not present at the place of occurrence whereas $13 \%$ mothers were present around the place of occurance. Before drowning, $45.1 \%$ victim was either playing, bathing or swimming in the water. Only $10.7 \%$ needed resuscitation, $25 \%$ were taken to health centre and reached the health centre within an hour, about a fifth $(22.6 \%)$ of them were admitted. Restriction in dangerous water activities, strengthening supervision of children might decrease the incidence of drowning while quick and effective medical response might prevent its fatal consequences.
\end{abstract}

Ibrahim Med. Coll. J. 2015; 9(2): 37-41

\section{Introduction}

Drowning is the process of experiencing respiratory impairment from submersion/immersion in liquid. Its outcomes are death, morbidity, and no morbidity..$^{1,2}$ Non-fatal drowning is the unintentional submersion in open water reservoir and household water containers with or without morbidity and no fatal consequence within 24 hours. ${ }^{3}$ Drowning has been identified as a major killer of children in both developed and developing countries. Children younger than 5 years old account for nearly $40 \%$ of all drowning fatalities..$^{4-7}$ In 1-4 year old children, drowning is the second leading cause of injury death in the United States and Africa and the leading cause in Australia. ${ }^{8}$ There are an estimated 500,000 significant submersions in the United States each year; 50,000 of these require medical intervention. As many as $50 \%$ of all submersion victims are declared dead at the scene and never referred to medical facilities for care ${ }^{8,9}$ For every death in child drowning, four cases are hospitalized and 16 receive emergency care for non-fatal drowning at the point of occurance. ${ }^{10}$

Children aged 1-4 years are at a high risk of death from drowning in rural Bangladesh. In Bangladesh, there are limited studies on the magnitude and risk factors of drowning. One study reveals that non-fatal

Address for Correspondence:

Mr. Syed Hassan Abdullah, Commanding officer, Bangladesh Army 
drowning is several times higher $(118 / 100,000)$ than the fatal drowning $(28.6 / 100,000){ }^{11}$

Although, in addition to mortality due to drowning, it is a major cause of morbidity for children while nonfatal drowning yet remains poorly understood. Most previous studies on drowning focused on description of drowning mortality and trends. ${ }^{11-13}$ There are few international studies done on non-fatal drowning in China $^{14-16}$ USA $^{17-19}$ and Australia. ${ }^{20-22}$

Every day in our country, 46 children die by drowning, two in every hour, where as 180 children suffer from some forms of injury from non-fatal drowning. ${ }^{13,23}$ Rural children are more vulnerable to near drowning. We must have adequate knowledge on risk and other associated factors of drowning and non-fatal drowning in rural Bangladesh to take preventive and necessary medical measures to protect children from drowning injury and fatality.

This exploratory study was an attempt to find out the issues and factors associated with non-fatal drowning cases in a rural area of Bangladesh.

\section{Methodology}

This community based descriptive study was undertaken in Raigonj sub-district of Sirajgonj district in Bangladesh, an area characterized by number of rivers, ponds and ditches which made the area prone to drowning. Raiganj sub-district is located about 130 $\mathrm{km}$ north west of capital Dhaka. The study included 122 children of $1-5$ years of age with at least one experience of non-fatal drowning event between January 2010 to April 2011. Participants were selected from the existing surveillance database of Centre for Injury Prevention and Research, Bangladesh (CIPRB).

Mothers of index children were interviewed using a pretested semi-structured questionnaire in Bengali. The questionnaire was pretested and finalized after necessary modifications. A check list was prepared to observe certain environmental variables. Data were collected on variables related to socio-economic status and occurrence of non-fatal drowning. Statistical Package for Social Sciences (SPSS) version 17.0 was used to analyse the data. The study was approved by the Ethical Committee of National Institute of Preventive and Social Medicine (NIPSOM), Bangladesh. Informed consent was obtained from mothers after explaining the purposes of the research.

\section{Results}

Sex distribution of 122 non-fatal drowning cases was almost equal between boys (62) and girls (60). Mean age of the children was 43.8 months and $56.6 \%$ of children was between 2-4 years of age while $27 \%$ was more than 4 years of age.

Parental characteristics of the 122 participants revealed that $65.5 \%$ mothers age was less than 30 years of age. Majority of the parents were illiterate (mothers $59 \%$ and fathers $57.4 \%$ ). Regarding father's occupation $44.4 \%$ was daily labourer followed by farmers (28.7\%). The detail socio-demographic characterstics is shown in Table-1. Monthly family expenditure was on

Table-1: Parental Socio-demographic and economic characteristics of the parents of enrolled participants $(n=122)$

\begin{tabular}{|c|c|c|}
\hline Characteristics & Number & $\%$ \\
\hline \multicolumn{3}{|c|}{ Mothers' age (in years) } \\
\hline$<25$ & 51 & 41.8 \\
\hline $25-29$ & 29 & 23.8 \\
\hline $30-34$ & 37 & 30.3 \\
\hline$>35$ & 5 & 4.1 \\
\hline$M e a n \pm S D$ & \multicolumn{2}{|c|}{$27.18 \pm 4.41$} \\
\hline \multicolumn{3}{|l|}{ Marital status } \\
\hline Married & 100 & 82.0 \\
\hline Single mother & 22 & 18.0 \\
\hline \multicolumn{3}{|c|}{ Mothers' educational level } \\
\hline Illiterate & 72 & 59.0 \\
\hline Up to class $\mathrm{V}$ & 38 & 31.2 \\
\hline class VI to IX & 6 & 4.9 \\
\hline SSC and above & 6 & 4.9 \\
\hline \multicolumn{3}{|c|}{ Fathers' educational level } \\
\hline Illiterate & 70 & 57.4 \\
\hline up to class $\mathrm{V}$ & 33 & 27.0 \\
\hline class VI to IX & 12 & 9.9 \\
\hline SSC and above & 7 & 5.7 \\
\hline \multicolumn{3}{|c|}{ Fathers' occupation } \\
\hline Labourer & 48 & 44.4 \\
\hline Farmer & 31 & 28.7 \\
\hline Business & 19 & 17.6 \\
\hline Service & 19 & 9.3 \\
\hline \multicolumn{3}{|c|}{ Monthly family expenditure (in taka) } \\
\hline$<4000$ & 46 & 37.7 \\
\hline $4000-8000$ & 70 & 57.4 \\
\hline$>8000$ & 6 & 4.9 \\
\hline$M e a n \pm S D$ & \multicolumn{2}{|c|}{$5289.90 \pm 2935.40$} \\
\hline \multicolumn{3}{|c|}{ Standard of living } \\
\hline Poor & 111 & 91.0 \\
\hline Good & 11 & 9.0 \\
\hline
\end{tabular}


Table-2: Distribution of non-fatal drowning events $(n=122)$

\begin{tabular}{lcc}
\hline Characteristics & n & \% \\
\hline $\begin{array}{l}\text { Seasonal variation of } \\
\text { drowning occurrence }\end{array}$ & & \\
Winter & 24 & 19.7 \\
Summer & 36 & 29.6 \\
Monsoon & 62 & 50.8 \\
Time of day when event occurred & & \\
6 to 10 am & 42 & 34.4 \\
10 am to 2 pm & 65 & 53.3 \\
2 to 6 pm & 13 & 10.7 \\
6 pm and after & 2 & 1.6 \\
Place of drowning & & \\
Within home premises & 10 & 8.2 \\
Outside home & 112 & 91.8 \\
$\quad$ - Pond & 56 & 45.9 \\
$\quad$ - Ditch & 26 & 21.3 \\
$\quad$ - River & 23 & 18.9 \\
$\quad$ - Others & 7 & 5.7 \\
Distance of place of drowning & & \\
from home (meter) & & \\
Within 10 & 45 & 40.2 \\
11-25 & 28 & 25.0 \\
More than 25 & 39 & 34.8 \\
\hline
\end{tabular}

average, 5290 Taka. About $95 \%$ families had monthly expenditure Tk. 8000 or less indicative of low socioeconomic condition. A variable was created to assess the living standard considering the construction material of the dwelling house and ownership of water source which showed that $91 \%$ participants had poor living standard (Table 1).

Monsoon was appeared as the most vulnerable time as $50.8 \%$ children experienced the event in this season, followed by summer $(29.5 \%)$. Most common time $(53.3 \%)$ for occurrence of drowning was between 10 am to 2 pm followed by 6-10 am (34.4\%). Most of the drowning event occurred in water reservoirs outside the home $(91 \%)$, rest were within home premises. Vulnerable items in home premises was water tub and drum. Outside the home premises pond appeared as the most common place (50.5\%) followed by shallow ditches $(23 \%)$ and river (20\%). Highest $(40.1 \%)$ drowning event occurred within 10 meter of their residence and $36.9 \%$ were more than 25 meter away from home (Table 2).

During the occurrence of accident, $47.5 \%$ mothers were busy with their usual house-hold works, followed by $20.5 \%$ mother who went outside for livelihood. At the time of occurrence $45.1 \%$ children were bathing or swimming in the water reservoir and $31 \%$ playing near the reservoir. Mothers were asked about accompanying person of child and their age during this non-fatal event. Around $22 \%$ children were not accompanied by anyone. In spite of adult supervision, $34 \%$ children also had drowning (Table 3 ).

Respondents were asked about the measures taken after drowning. Only thirteen children received immediate on the spot resuscitation, $25 \%$ children were taken to health centre. Cases could reach health centre within an hour; only one child required more than an hour.

\section{Table-3: Events while drowning took place}

\begin{tabular}{lccc}
\hline Events & n & \% \\
\hline Mothers' involvement during occurrence & & \\
Household work & 58 & 47.5 \\
Personal work - rest, having meal etc. & 23 & 18.9 \\
Working outside home & 25 & 20.5 \\
Accompanying child & 16 & 13.1 \\
Children's involvement during occurrence & \\
Bathing /swimming in water reservoir & 55 & 45.1 \\
Playing near water reservoir & 39 & 32.0 \\
Slip or fall while crossing water & 21 & 17.2 \\
Others & 7 & 5.7 \\
Accompanying person during occurrence & & \\
None & 28 & 23.0 \\
Parents/caregivers & 20 & 16.4 \\
Siblings/relatives & 42 & 34.4 \\
Friend/peer - children & 32 & 26.2 \\
Age of accompanying persons (in years) & & \\
Up to 5 & 17 & 18.1 \\
6- 11 & 38 & 40.4 \\
18 and above & 39 & 41.5 \\
\hline
\end{tabular}

Table-4: Measures taken after non-fatal drowning event

\begin{tabular}{lcc}
\hline Measures & $\mathbf{n}$ & $\mathbf{\%}$ \\
\hline Resuscitation after recovery & & \\
No & 109 & 89.3 \\
Yes & 13 & 10.7 \\
Taken to health center & & \\
No & 91 & 74.6 \\
Yes & 31 & 25.4 \\
Treatment received in health center & & \\
No treatment required & 10 & 8.2 \\
Emergency care & 14 & 11.5 \\
Admitted in Health center & 7 & 5.7 \\
\hline
\end{tabular}


After arrival in health centre seven children got admitted, 14 left the centre after receiving emergency care, rest 10 did not require any medical management (Table 4).

\section{Discussion}

It has been mentioned earlier that most of the previous studies related to drowing in Bangladesh focused on description of drowning mortality and trends. ${ }^{9,11,12,16,20,23}$ No community based study was found either to characterize non-fatal drowning or explore its associated factors in Bangladesh. Therefore, initiative was taken to conduct this community based descriptive study through household visits. Mean age of children were 43.80 months. Boys and girls equally were the victims. Findings showed that most of the parents were illeterates. Educated mothers were aware about the child care. Cases of non-fatal drowning was more in younger mothers which indicated that maturity in looking after the child might be contributing factor to reduce occurrence of non-fatal drowning. ${ }^{13}$ Children were less vulnerable when mothers' age was more than 30 years. Similar findings were observed in several studies in China. ${ }^{3,8,14-16}$

In this study $91 \%$ non-fatal drowning incidents occured in natural bodies of water outside the home premises. The finding is similar with fatal drowning data in China. ${ }^{8}$ But it, is different from non-fatal drowning data of USA where $75 \%$ of non-fatal drowning occurred in swimming pools. ${ }^{18}$ This indicates that the locations of non-fatal drowning are likely to be different between and within countries due to geographical and economic differences. Seasonal variations in child drowning also observed in this study. About half of the drowining events occurred in rainy season. Bangladesh is a tropical country and during monsoon heavy rainfall floods and fills up the rivers, canals, ponds and ditches. For this, children have more chance to be exposed to wider area for risk of drowning. Hot summer season is also appeared as vulnerable (29\%) as hot and humid temperature allure kids to more water fun which may end up in drowning in many cases. This trend has been observed in other studies in both developing and developed countries. ${ }^{8,16,18}$ Total $53.3 \%$ incidents occurred between 10 am to $2 \mathrm{pm}$ followed by morning. During these time periods parents in rural area usually remain busy with livelihood or household works, elder siblings stay in school resulting in unattended kids.
Household water reservoirs such as drums, water tub were also found unsafe. Of the 122 cases, 11 non-fatal drowning cases occurred in household reservoirs. Among the outside places, ponds were noticed as the most common place of drowning. In rural Bangladesh, playing in the water reservoir is common and thus the place of drowning. Swimming inability of the children and absence of adult supervision resulted into drowning of children. About a third of study sample drowned within 10 meter of their home premises. Similar findings are observed in another study in Bangladesh and China. ${ }^{3,23}$ It indicates that lack of supervision even for a few minutes may lead to drowning. Despite accompaniment of adult persons, more than half (54\%) of children experienced drowning. Negligence and inadequate supervision may be the reason of the incident. At the time of occurrence of drowning $47.8 \%$ mothers were busy with their household work and $20.9 \%$ were not at home.

Early rescue and management, either on spot or in health centre, play vital role in preventing fatal outcome of drowning. In this study $10.7 \%$ cases received immediate resuscitation and 31 cases were taken to health centre and mostly reached the health facility within an hour. Minimum time loss before resuscitation is one of the key factors to save the life of drowning victim. ${ }^{18}$ These findings are supported by studies in China and Australia. ${ }^{8,21}$

The present study suggested that non-fatal drowning most commonly noted in rainy season, during the mothers' busy time and in ponds around the households. Restriction in playing in ponds or in water reservoirs and strengthening supervision of children might decrease the incidence of non-fatal drowning. Rapid and effective response is the priority point of consideration for prevention of any fatal consequences of the drowning.

\section{References}

1. Krug E. Injury: A leading cause of the global burden of disease. Geneva: Department of Injuries and Violence Prevention, Non-communicable Diseases and Mental Health Cluster, World Health Organization 2002; 50.

2. Beeck E, Branche CM, Szpilman D Modell J, Bierens JJLM. A new definition of drowning: Towards documentation and prevention of a global public health problem. Bull World Health Organ 2005; 83(11): 853-856. 
3. Wen JM, Shao PN et al. An analysis of risk factors of non-fatal drowning among children in rural areas of Guangdong Province, China: A case-control study. BMC Public Health 2010; 10: 156.

4. Rahman A, Giashuddin SM, Svanström L, Rahman F. Drowning - a major but neglected child health problem in rural Bangladesh: implications for lowincome countries. International Journal of Injury Control and Safety Promotion 2006; 13(2): 101-105.

5. Peden M, McGee K, Sharma G: The injury chart book: A graphical overview of the global burden of injuries. Geneva: World Health Organization 2002.

6. Krug EG, Sharma GK, Lozano R. The global burden of injuries. Am J Public Health 2000; 90: 523-526.

7. Barss P. Drowning and other Water-related injuries in Canada. 1991-2000, Module 1: overview. The Canadian Red Cross Society 2006.

8. Yang L, Nong Q. Risk factors for childhood drowning in rural regions of a developing country: A case-control study. Injury Prevention 2007; 13: 178-182.

9. Wintemute G, Kraus J, Teret S, Wright M. Drowning in childhood and adolescence: a population-based study. American Journal of Public Health 1987; 77: 830-832.

10. Moon RE, Long RJ. Drowning and near-drowning. Emergency Medicine 2002; 14: 377-386.

11. Rahman A, Mashreky SR, Chowdhury SM, Giashuddin MS, Uhaa IJ, Shafinaz S et al. Analysis of the childhood fatal drowning situation in Bangladesh: exploring prevention measures for low income countries. Injury Prevention 2009; 15: 75-79.

12. Iqbal A. Childhood mortality due to drowning in rural matlab of Bangladesh: magnitude of the problem and proposed solutions. J Health Popul Nutr 2007; 25(3): 370-376.
13. Rahman A, Rahman F, Shafinaz S, Linnan M. Bangladesh Health and Injury Survey: Report on children 2005; (5): 49-56. available at: http://www. unicef.org/bangladesh/Bangladesh_Health_and_Injury_ Survey-Report_on_Children.pdf

14. Yu M, Gong W, Han X, Hu R. An analysis on the cause of injury death in Zhejiang Province, 1999-2001. Zhejiang Preventive Medicine 2004; 16(3): 3-5.

15. Ma WJ, Xu YJ, Zhang YR. The study on death pattern and burden of disease in Guangdong province, China. Guangzhou: The economic press of Guangdong province 2008.

16. Liu J, Qu H. Analysis on drowning among children under 5 years in Nanjing during 1996-2000. Jiangsu Health Care 2001; 3(3): 14-15.

17. Wintemute GJ. Childhood drowning and near-drowning in the United States. Am J Dis Child 1990; 144: 663-9.

18. Gilchrist J, Gotsch K, Ryan G. Non-fatal and fatal drowning in recreational water settings-United State, 2001-2002. JAMA 2007; 292(2): 164-166.

19. Calder RA, Clay CY. Drowning in Florida 19771986. J Flo Med Assoc 1990; 77: 679-82.

20. Mackie IJ. Patterns of drowning in Australia, 1992-1997. Medical Journal of Australia 1999; 171: 587-590.

21. Pitt WR, Balanda KP. Childhood drowning and near drowning in Brisbane: The contribution of domestic pools. Med J Aust 1991; 154: 661-5.

22. Silva DT, Ruben AR, Wronski I, Stronach P, Woods M. Excessive rates of childhood mortality in the northern territory. J Paediatr Child Health 1998; 34(1): 63-68.

23. Ahmed MK, Rahman M, Ginneken JV. Epidemiology of child death due to drowning in Matlab, Bangladesh. International Journal of Epidemiology 1999; 28: 306-311. 